\title{
OPORTUNIDADES DE APRENDIZAGEM DE CONCEITOS DO CÁLCULO DIFERENCIAL E INTEGRAL EM UMA ATIVIDADE DE MODELAGEM MATEMÁTICA
}

\author{
LEARNING OPPORTUNITIES OF DIFFERENTIAL AND INTEGRAL CALCULUS CONCEPTS \\ IN A MATHEMATICAL MODELING ACTIVITY
}

\author{
DANIELA BARBIERI VIDOTTI* \\ LILIAN AKEMI KATO**
}

\section{RESUMO}

Nessa pesquisa, consideramos os erros matemáticos, produzidos na resolução de um problema, como potenciais geradores de dúvidas construtivas, uma vez que conduzem os alunos a investigações matemáticas, as quais implicam em diferentes oportunidades de aprendizagem. Nesse viés, a Modelagem no âmbito da Educação Matemática por suas características investigativas e temáticas, traz contribuições importantes para o ensino e aprendizagem de conceitos matemáticos. Nesse estudo visamos identificar e discutir algumas das possibilidades do uso dos erros matemáticos como oportunidades de aprendizagem de alguns conceitos do Cálculo Diferencial e Integral. A pesquisa, de cunho qualitativo, desenvolvida com acadêmicos do quarto ano do curso de Licenciatura em Matemática revelou possibilidades para usos dos erros como trampolins para pesquisa, os quais foram desencadeados espontaneamente no decorrer da atividade de Modelagem Matemática, proporcionando reflexões que extrapolam o âmbito do conteúdo específico do Cálculo.

Palavras-chave: Análise de erros. Integral Dupla. Licenciatura em Matemática.

\section{ABSTRACT}

In the following research, we consider the errors produced during a mathematical problem solving as potential generators of constructive doubt, since such errors lead students to the mathematical investigations, which imply multiple learning opportunities. In this bias, the Mathematical Education Modeling due to its investigatory and thematic features, brings important contributions to mathematical teaching and learning concepts. In this study, we aimed to recognize and argue some of the possibilities of the use of mathematical errors as learning opportunities of some Differential and Integral Calculus concepts. The research, of a qualitative nature, developed with students of the fourth year of the Mathematics Degree Course revealed possibilities for using errors as springboards for inquiry, which were triggered spontaneously in the course of the Mathematical Modeling activity, providing reflections in these future teachers, which go beyond the specific scope of the Calculus content.

Keywords: Error analysis. Double Integral. Degree in Mathematics.

\footnotetext{
* Doutora em Educação para a Ciência e a Matemática pela Universidade Estadual de Maringá (UEM). Professora Adjunta do Colegiado de Matemática da Universidade Estadual do Paraná - Campus de Paranavaí/PR (UNESPAR). E-mail: dnbarbieri@hotmail.com. Orcid: https://orcid.org/ 0000-0002-8744-7600

** Doutora em Matemática Aplicada pela Universidade Estadual de Campinas (Unicamp). Professora Associada do Departamento de Matemática e do Programa de Pós-Graduação em Educação para a Ciência e a Matemática da Universidade Estadual de Maringá (UEM). E-mail: lilianakemikato@gmail.com. Orcid: https://orcid.org/0000-0001-8770-3873
} 


\section{INTRODUÇÃO}

Em contextos escolares, nas disciplinas de Matemática, é comum nos depararmos com os erros cometidos pelos alunos em suas produções matemáticas. Muitas vezes, um erro pode evidenciar inúmeras dificuldades relacionadas à compreensão de um determinado conceito ou operação matemática. Por vezes, discutir com os alunos sobre 0 erro cometido, ou partir das respostas errôneas para elaborar novas questões, ou instigá-los a compreender em que e porque erraram, constituem ações que podem contribuir para esclarecer dúvidas que, se não resolvidas, podem prevalecer e tornarem-se empecilhos para aprendizagem na vida escolar. Nessa direção, o erro ganha um novo status, assumindo um sentido positivo nos processos de ensino e de aprendizagem, à medida que passamos a reconhecê-lo como possibilidade de construção de conhecimentos.

Esse papel que 0 erro pode desempenhar no ensino, tem sido defendido por pesquisadores que trabalham com a análise de erros em Educação Matemática, por influência de teorias construtivistas de aprendizagem, consolidadas desde a segunda metade do século XX, a partir dos trabalhos de Jean Piaget (ASTOLFI, 1999; CURY, 2008). A pesquisadora Borasi $(1985,1996)$, por exemplo, defende a possibilidade de explorar o potencial dos erros para estimular a pesquisa e a descoberta, ou seja, usar os erros como "trampolins para a aprendizagem". Nesse sentido, o foco não é a eliminação do erro, mas o aprofundamento do conteúdo, a partir da exploração do próprio erro.

Nessa perspectiva, alguns estudos têm sido realizados no contexto do Cálculo Diferencial Integral (CDI) como, por exemplo, o de Rocha e Wagner (2017) que desenvolveram uma proposta pedagógica com alunos da disciplina de Cálculo I dos cursos de Engenharia Agronômica e Ciências Agrárias abordando o conteúdo de limites de funções reais. Assumindo a análise de erros como estratégia de ensino, na perspectiva de Borasi (1996), os autores apontaram que as estratégias adotadas favoreceram a aprendizagem de conceitos de CDI além de provocarem uma mudança de postura de alunos e professor face ao erro, uma vez que a turma passou a considerar acertos e erros nas aulas para a reflexão e a argumentação sobre o conceito de limite.

Consonante a essa abordagem de ensino, encontramos outras pesquisas como Cury (2008), Braga (2009), Müller (2015), Kashefi, Zaleha e Yudarah (2012), Kashefi et al. (2012), Añino et al. (2014) e Brito e Nunes (2017). Vale ressaltar que essas pesquisas também têm contribuído para identificar as dificuldades dos alunos em relação à compreensão e aplicação de conceitos de CDI.

Com relação à aprendizagem de CDI em várias variáveis, Kashefi, Zaleha, Yudarah (2010; 2011) apontaram que os alunos têm dificuldades para encontrar o domínio e esboçar o gráfico de funções de várias variáveis, bem como para resolver problemas relacionados a derivadas parciais e integrais múltiplas. Além disso, Vidotti e Kato (2018) identificaram dificuldades relacionadas à compreensão do conceito de limite de funções de várias variáveis, bem como à aplicação de propriedades para calcular o limite. Esses estudos convergem para a necessidade de ações pedagógicas que ajudem os alunos a superarem as dificuldades de aprendizagem desses conceitos de CDI em várias variáveis. Todavia, a literatura de Educação Matemática no Ensino Superior tem apontado incipiência de estudos que investiguem sobre essa temática (ALVES, 2011; KASHEFI et al., 2012).Com intuito de contribuirmos com reflexões nesse campo de investigação, propomos nesta pesquisa, apoiados nos pressupostos teóricos indicados por Borasi (1996) identificar e discutir possibilidades para 0 uso dos erros matemáticos como oportunidades de aprendizagem de conceitos do Cálculo Diferencial e Integral no desenvolvimento de uma atividade de Modelagem Matemática'.

1 Ao longo deste texto adotamos o termo Modelagem para nos referir à Modelagem Matemática no âmbito da Educação Matemática. 
Consideramos a Modelagem como uma prática de caráter investigativo, temática e que trabalha com a Matemática (KLÜBER, 2012) o que, de acordo com Braga (2009) e Vidotti (2019), possibilita que os erros (quando surgem) se tornem observáveis aos próprios alunos e possam, assim, na perspectiva adotada nesse trabalho, estimular a pesquisa e a descoberta.

No âmbito da Educação Matemática, nas últimas décadas, diversos estudos têm relatado o uso da Modelagem no ensino e na aprendizagem de CDI (FRANCHI, 1993; ARAÚJO, 2002; BORSSOI, 2004; VERTUAN, 2007; SANTOS, 2008; BRAGA 2009; BASSANEZI, 2013; BARROS, 2017), apresentando argumentos favoráveis à sua inserção nas aulas de CDI. 0 trabalho de Braga (2009), por exemplo, aponta que "[...] 0 ambiente de ensino e aprendizagem gerado por meio da Modelagem Matemática favorece 0 tratamento do erro matemático dos alunos" (BRAGA, 2009, p. 153).

As justificativas apresentadas mostram a relevância dessa pesquisa, que tem por objetivo investigar: Que possibilidades de aprendizagem se revelam a partir dos erros cometidos pelos alunos em uma atividade de Modelagem Matemática envolvendo conceitos de Cálculo Diferencial e Integral? Para tanto, na sequência, expomos os pressupostos teóricos e aspectos metodológicos da pesquisa, bem como a análise do desenvolvimento de uma atividade de Modelagem realizada por alunos da Licenciatura em Matemática de uma universidade pública paranaense.

\section{PRESSUPOSTOS TEÓRICOS}

Nessa pesquisa concebemos 0 erro como oportunidade de aprendizagem em conformidade com os pressupostos de Borasi (1996), segundo os quais os erros em Matemática podem ser considerados como "trampolins para pesquisa", ou seja, como oportunidades para gerar dúvidas e questionamentos que, por sua vez, conduzem os alunos a explorações e aprendizagens. Tecnicamente, essa abordagem consiste em "capitalizar erros no ensino de matemática ${ }^{3}$ ". Fundamentada em ideias de Thomas Kuhn, Imre Lakatos, Jean Piaget e Gérard Vergnaud acerca da filosofia da Ciência e aprendizagem da Matemática, a autora distinguiu e explorou, a partir de inúmeras experiências de ensino e de aprendizagem, diferentes formas de usar erros como trampolins para pesquisa em Matemática.

Desse modo, Borasi (1996) identificou três níveis do discurso matemático que influenciam na forma como os erros são capitalizados: (i) nível de tarefa; (ii) nível de conteúdo; e (iii) nível de matemática. Especificamente, dependendo desses níveis, a análise de erros pode conduzir 0 aluno à:

Realizar uma tarefa matemática específica - isto é, resolver um problema, forming a computation, attempting to prove a result, producing an ac-efetuar um cálculo, tentar provar um resultado, produzir uma ceptable definition for a given concept, and so on.definição aceitável para um determinado conceito, entre outros.

Aprender algum conteúdo técnico-matemático - seja um conceito, rule, or topic, such as limit, limit operations, or calculus, respectively.regra ou tópico, como limite, operações de limite ou cálculo, respectivamente.

Aprender sobre a natureza da Matemática - isso pode envolver a compreensão de standing metamathematical notions such as definition, proof, or algo-noções matemáticas, tais como definição, prova ou algorithm;ritmo; becoming aware of helpful heuristics as well as of their domain oftomando conhecimento de heurísticas úteis, bem como de seu domínio de application and limitations;aplicação e limitações;

\footnotetext{
2 "Springboards for Inquiry".

3 "Capitalizing on errors in mathematics instruction".
} 
appreciating what characterizes mathematicalapreciando o que caracteriza o pensamento matemáticothinking and mathematics as a discipline; e a matemática como disciplina; and so on.e assim por diante (BORASI, 1996, p. 115-116, tradução nossa).

De modo concomitante, e independente do nível do discurso matemático, Borasi (1996) identificou também diferentes posturas de aprendizagem que parecem influenciar as atitudes e objetivos dos alunos no estudo de erros:

- Postura de remediação4: quando tanto a questão investigada quanto a sua resposta são predeterminadas e conhecidas pelo professor, e 0 aluno já está ciente de que sua resposta está incorreta; logo, espera-se que, analisando essa resposta, seja possível identificar 0 erro e repará-lo.

- Postura de descoberta5: quando o aluno está aprendendo algo novo ou tentando resolver um problema e assim, naturalmente, pode vir a tomar passos na direção errada, sem perceber que está errando, mas sente-se instigado a examinar criticamente a sua reposta para determinar se está correta ou não. Aqui a questão investigada é predeterminada e o professor reconhece o resultado correto ou incorreto.

- Postura de pesquisa6: quando nem a questão e nem a sua resposta são, necessariamente, predeterminadas, e 0 erro torna-se um estímulo para redefinir a tarefa original, iniciando explorações e reflexões em outras direções.

Ao combinar essas três posturas de aprendizagens com os três níveis do discurso matemático definidos anteriormente são possíveis nove diferentes formas de explorar os erros em matemática como trampolins para pesquisa, denominada por Borasi (1996, p. 138, tradução nossa) de "taxionomia de usos dos erros como trampolins para a pesquisa ${ }^{7 "}$. A autora resume em um quadro sucessivamente aperfeiçoado (BORASI, 1996) essas possibilidades, conforme apresentamos no Quadro 1:.

Quadro 1 - Taxionomia de usos dos erros como trampolins para a pesquisa

\begin{tabular}{|c|c|c|c|}
\hline \multirow{2}{*}{$\begin{array}{c}\text { Postura de } \\
\text { Aprendizagem }\end{array}$} & \multicolumn{3}{|c|}{ Nível do discurso matemático } \\
\hline & $\begin{array}{c}\text { Realização de uma tarefa matemática } \\
\text { específica (Tarefa) }\end{array}$ & $\begin{array}{l}\text { Compreensão de algum conteúdo } \\
\text { técnico-matemático (Conteúdo) }\end{array}$ & $\begin{array}{c}\text { Compreensão sobre a natureza da Mate- } \\
\text { mática(Matemática) }\end{array}$ \\
\hline Remediação & $\begin{array}{l}\text { Análise de erros detectados, para compre- } \\
\text { ender o que houve de errado e corrigir, de } \\
\text { forma a realizar a tarefa com sucesso. }\end{array}$ & $\begin{array}{l}\text { Análise de erros detectados, para } \\
\text { esclarecer más interpretações de } \\
\text { um conteúdo técnico-matemático. }\end{array}$ & $\begin{array}{l}\text { Análise de erros detectados, para esclare- } \\
\text { cer más interpretações sobre a natureza da } \\
\text { Matemática ou de conteúdos específicos. }\end{array}$ \\
\hline Descoberta & $\begin{array}{l}\text { Uso construtivo de erros no processo de } \\
\text { resolução de um novo problema ou tarefa; } \\
\text { monitoramento do trabalho de alguém, } \\
\text { para identificar erros potenciais. }\end{array}$ & $\begin{array}{l}\text { Uso construtivo de erros ao } \\
\text { aprender novos conceitos, regras, } \\
\text { tópicos, etc. }\end{array}$ & $\begin{array}{l}\text { Uso construtivo de erros ao aprender } \\
\text { sobre a natureza da Matemática ou de } \\
\text { algum conteúdo matemático. }\end{array}$ \\
\hline Pesquisa & $\begin{array}{l}\text { Erros e resultados intrigantes motivam } \\
\text { questões que geram pesquisas em novas } \\
\text { direções e servem para desenvolver novas } \\
\text { tarefas matemáticas. }\end{array}$ & $\begin{array}{l}\text { Erros e resultados intrigantes } \\
\text { motivam questões que podem levar } \\
\text { a novas perspectivas sobre um } \\
\text { conceito, regra ou tópico não con- } \\
\text { templado no planejamento original. }\end{array}$ & $\begin{array}{l}\text { Erros e resultados intrigantes motivam } \\
\text { questões que podem levar a insights e } \\
\text { perspectivas inesperadas sobre a } \\
\text { natureza da Matemática ou de algum } \\
\text { conteúdo matemático. }\end{array}$ \\
\hline
\end{tabular}

Fonte: Adaptado de Borasi (1996, p. 138, tradução nossa).

\footnotetext{
4 "Remediation stance".

5 "Discover stance".

6 "Inquiry stance".

7 "Taxonomy of Uses of Errors as Springboards for Inquiry".
} 
Cada uma dessas nove estratégias de exploração dos erros em sala de aula sugere diferentes implicações em termos de oportunidades de aprendizagem, dependendo do objetivo da tarefa e do nível do discurso matemático adotado, constituindo assim, elementos que embasam as discussões deste trabalho. De acordo com Borasi (1996), é possível transitar pelas diferentes estratégias de análise de erros, ou seja, pode-se partir, por exemplo, de uma atividade de descoberta/conteúdo e, dependendo do seu desenvolvimento, podem surgir elementos que levem professores e alunos a adotarem estratégias de remediação/tarefa.

Independente da estratégia adotada é necessário envolver os alunos na função de "corrigir" e "explicar" seus próprios erros, sendo que o professor deve criar situações que os tornem observáveis para os mesmos (BORASI, 1996). É nessa perspectiva que esse estudo se sustenta quando adotamos atividades de Modelagem Matemática como fomentadoras de momentos nos quais os erros (que surgirem) constituam instrumentos de motivação para novos desafios aos alunos. É importante destacar que não agimos na intencionalidade de promover (todas) as estratégias de usos dos erros apontadas no Quadro 1, pois queremos investigar, nesse espectro de possibilidades, quais delas surgem no desenvolvimento de uma atividade de Modelagem Matemática e suas implicações em termos de oportunidades de aprendizagem.

Considerando que na literatura de Modelagem Matemática o termo "erro" pode apresentar ambiguidades, faz-se necessário explicitar que nesta pesquisa estamos entendendo como erros cometidos pelos alunos as respostas (orais ou escritas) associadas às questões matemáticas provenientes do processo de Modelagem Matemática "[...] as quais estão em desacordo com as verdades aceitas pela comunidade acadêmica ou pelo professor" (CURY, 1994, p. 99).

A partir desses pressupostos, apresentamos na seção seguinte, os procedimentos metodológicos da pesquisa.

\section{PROCEDIMENTOS METODOLÓGICOS}

A pesquisa foi realizada à luz de orientações características da vertente qualitativa em Educação Matemática, conforme discutidas por Garnica (2004). Nesse âmbito, reconhecemos: que o contexto ao qual a pesquisa foi inserida, de certa forma, interferiu em seus resultados, tornando-os transitórios; não estabelecemos hipóteses a priori para a pesquisa, pois consideramos que elas surgem das reflexões ocorridas no decorrer de seu desenvolvimento; as ações da professorapesquisadora ${ }^{8}$ contribuíram para a não neutralidade da pesquisa, uma vez que a mesma participou da construção dos dados, configurando e conduzindo as aulas e, além do mais, as interpretações realizadas não dependeram de um método pré-definido, mas da própria pesquisadora que envolveu-se em um processo indutivo de interpretação dos dados, guiada por suas perspectivas e filtros; alguns aspectos da pesquisa, tais como configuração das atividades e instrumentos de coleta de dados, embora tenham sido previamente planejados, foram reconfigurados no decorrer da investigação, a partir de elementos imprevistos que foram surgindo.

Nesse viés, a questão norteadora foi delineada e a partir dela nos debruçamos sobre os dados coletados a fim de definirmos os procedimentos de análise. Neste texto, para atingir os objetivos assumidos, analisamos uma das atividades de Modelagem Matemática desenvolvidas em um curso

8 De acordo com Campos e Araújo (2015, p. 336) a relação dialética pesquisador|professor caracteriza-se "por uma alternância entre ênfase no papel de pesquisadora e no de professora" colocando ação e reflexão em diálogo. Esse duplo papel, de pesquisadora e professora, exercido por uma mesma pessoa é uma prática recorrente em pesquisas de Modelagem realizadas no contexto de uma prática pedagógica. 
de extensão, no qual participaram 11 acadêmicos do $4^{0}$ ano da Licenciatura em Matemática, de uma universidade pública paranaense.

Nessa atividade o tema "latinhas de alumínio" foi problematizado junto aos alunos, com intuito de estabelecer um problema real que pudesse ser solucionado com conceitos matemáticos abordados na disciplina de CDI II. A discussão na sala de aula culminou no estudo de propriedades geométricas das latinhas. A atividade foi desenvolvida em dois encontros de quatro horas-aula. Essas aulas foram gravadas por meio de áudio e vídeo; as gravações foram transcritas pela professora/ pesquisadora que juntamente com os registros escritos dos alunos e com as anotações em um diário de campo, constituíram os dados dessa pesquisa.

Esses instrumentos de coleta de dados foram usados de forma complementar, para que a professora/pesquisadora pudesse detectar os erros cometidos pelos alunos, bem como os encaminhamentos tomados a partir do reconhecimento desses erros pelos sujeitos envolvidos. Foi solicitado que os alunos não apagassem nenhum dos cálculos efetuados, pois entendemos que poderia prejudicar a realização da análise dos dados de forma fidedigna.

Para o desenvolvimento da atividade constituíram-se três grupos: G1) Paloma, Luana, Mara e Simão; G2) Brenda, Ana, Marcelo e Bia; e G3) Diana, Eliane e Babi. Esses alunos, cujos nomes são fictícios, já haviam cursado a disciplina de CDI II (Cálculo em várias variáveis), momento em que também tiveram contato com a Modelagem.

Considerando-se que nesta pesquisa era importante a mobilização de conceitos de CDI II, em função dos objetivos assumidos, os alunos também foram alertados que esses deveriam surgir na construção dos modelos matemáticos. Por essa razão, ao utilizarmos a Modelagem como estratégia de ensino e aprendizagem, assumimos a concepção de Bassanezi (2013, p. 13) que a entende como "[...] a arte de transformar problemas da realidade em problemas matemáticos e resolvê-los interpretando suas soluções na linguagem do mundo real". Nesse sentido, a Modelagem foi empreendida como um processo que alia teoria e prática na busca pela compreensão da realidade, sendo essencial a construção de um modelo matemático, isto é, "[...] um conjunto de símbolos e relações matemáticas que representam de alguma forma 0 objeto estudado" (BASSANEZI, 2013, p. 20).

Desse modo, o modelo matemático constitui-se em uma linguagem propícia à aplicação de proposições/teoremas matemáticos que permitem solucionar o problema em questão, independente de sua área de origem. Bassanezi (2013) classificou os modelos matemáticos de acordo com o tipo de matemática utilizada, em: (i) linear ou não linear; (ii) estático ou dinâmico; e (iii) educacional ou aplicativo. Na atividade relatada na próxima seção, a problematização do tema "latinhas de alumínio" direcionou a utilização de modelos do tipo "estáticos" representando a forma desses objetos por meio de funções de duas variáveis.

Com relação aos encaminhamentos da atividade, sua condução se deu em conformidade com as seis etapas indicadas por Bassanezi (2013) para o desenvolvimento de atividades de Modelagem em sala de aula: experimentação, abstração, resolução, validação, modificação e aplicação. Mas, dado 0 interesse em discutirmos possibilidades para o uso dos erros matemáticos como oportunidades de aprendizagem, não descrevemos como a atividade se desenvolveu mediante cada uma delas, mas em alguns episódios que denotam os usos dos erros pelos alunos. 


\section{DESCRIÇÃO E ANÁLISE DA ATIVIDADE DE MODELAGEM}

Para desenvolver essa atividade foi solicitado aos alunos que levassem para 0 encontro latinhas de bebidas vazias (cervejas, refrigerantes, sucos etc.). A atividade foi iniciada com a exibição de um víde $0^{9}$ que apresentava, resumidamente, 0 processo de fabricação das latas de alumínio para bebidas. Em seguida, iniciamos uma conversa a fim de problematizar esse tema: "0 que vocês gostariam de estudar sobre as latinhas de alumínio?" "Quais problemas poderiam ser estudados por meio do CDI II?" Vários itens foram listados na lousa, por sugestões dos alunos e também da professora/pesquisadora. Embora tivesse ficado livre o que investigar, ou seja, a problematização do tema sugerido, os três grupos optaram por: (i) escrever uma ou mais equações cujo gráfico representasse a superfície da latinha; e (ii) encontrar uma forma de calcular o volume da latinha com os conceitos do CDI II.

Para realizar esse trabalho, os alunos foram conduzidos a: (i) coletar informações para o problema, identificando as medidas de cada parte da latinha; (ii) elaborar um modelo matemático para representar a superfície da lata, partindo de modelos prontos e levantando hipóteses necessárias para fazer essa representação; e (iii) calcular o volume da lata, utilizando integrais duplas.

Na Figura 1, apresentamos as denominações de cada parte da lata, subdividida pelos alunos para realizarem esse estudo. 0 espaço que compreende o fundo da lata, indicado na Figura 1 como parte cônica do fundo, foi desprezado por pelos grupos, pois consideraram que 0 volume interno dessa parte é pequeno e não faria muita diferença na estimativa final do volume.

Figura 1 - Ilustração da lata utilizada na atividade com as respectivas denominações de suas partes

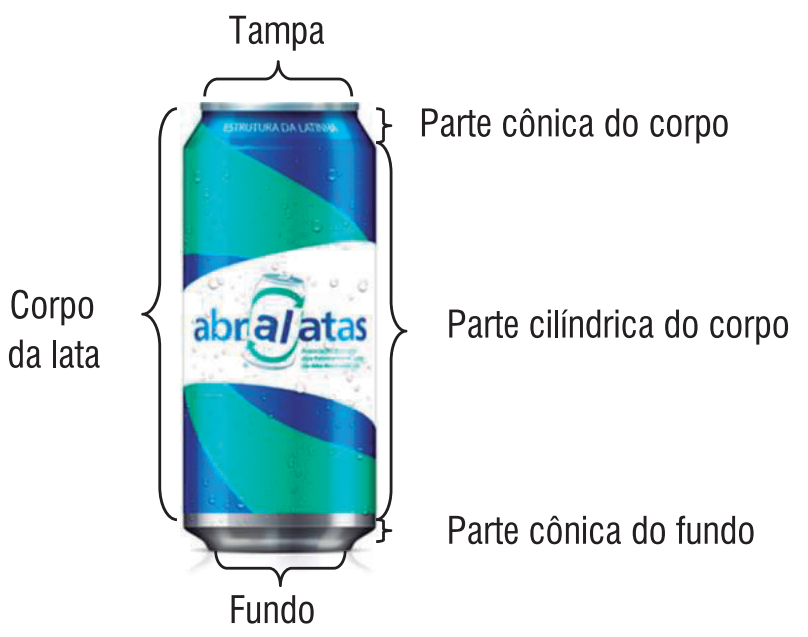

Fonte: Vidotti (2019, p. 172) adaptado de ABRALATAS (2017).

Após terem determinado as medidas da lata, os alunos procuraram estabelecer uma equação que representasse matematicamente a parte cilíndrica do corpo da lata. Para isso, pesquisaram na em Stewart (2011, p. 766) a definição de um cilindro: "[...] é uma superfície constituída de todas as retas (chamadas geratrizes) que são paralelas a uma reta dada e que passam por uma curva

90 vídeo é de autoria da ABRALATAS (Associação brasileira dos fabricantes de latas de alumínio). Disponível em http://www.abralatas.org.br/ \#containerLata Acesso em 05 de abr. de 2017. 
plana". Visto que a lata tem formato circular, perceberam que a curva plana deveria ser a equação da circunferência, $x^{2}+y^{2}=r^{2}$.

Primeiro episódio de erro: Nessa fase, os integrantes do G3 confundiram o raio com o diâmetro da circunferência na equação, configurando um erro, pois escreveram $x^{2}+y^{2}=6,5^{2}$ ao invés de $x^{2}+y^{2}=3,25^{2}$. Além disso, nos seus registros, as medidas dos diâmetros da base do cilindro, da circunferência da tampa e do fundo da lata, foram denominadas de "circunferências" ao invés de "diâmetros". Diante desses equívocos, a professora/pesquisadora sugeriu que 0 G3 realizasse a representação dessa parte cilíndrica da lata no espaço cartesiano, inserindo as medidas dos elementos da lata, conforme ilustrado na Figura 2.

Figura 2 - Esboço da parte cilíndrica da lata no espaço cartesiano

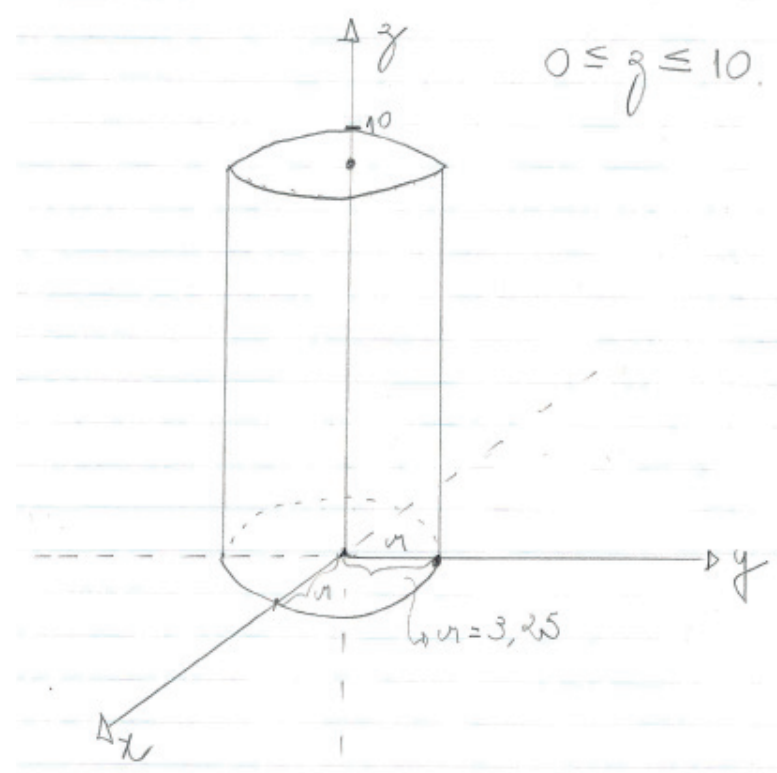

Fonte: Vidotti (2019, p. 175).

Após concluir a representação geométrica, uma das alunas desse grupo não havia compreendido qual foi o erro cometido, conforme evidencia o trecho a seguir:

Eliane: A gente mediu errado?

Babi: Não. A gente mediu certo, só que a gente mediu inteiro não foi? Então isso é o diâmetro. não é o raio.

Eliane: $E$ a gente escreveu circunferência, então vou riscar e colocar diâmetro.

Essa ação de desenhar a latinha foi necessária para que as alunas reconhecessem os elementos que caracterizam e identificam a superfície cilíndrica e suas dimensões. Por isso, nesse episódio, identificamos que essas alunas assumiram uma postura de descoberta/conteúdo desencadeada pelo erro "confundir o raio com o diâmetro da base na equação do cilindro" e reconheceram essa confusão. 
No grupo G2, Ana levantou o seguinte questionamento: "a variável z não aparece na equação do cilindro, então como vamos delimitar a altura do cilindro?". Na ocasião, a professora/pesquisadora explicou que eles poderiam partir da hipótese de que estavam considerando a parte da superfície cilíndrica de equação $x^{2}+y^{2}=3,25^{2}$ compreendida entre os planos horizontais de equações $z=0 \mathrm{e}$ $z=9,8$, visto que esta foi a medida da altura da parte cilíndrica da lata identificada pelo grupo. Essas informações foram suficientes para delimitarem a região de integração que seria utilizada para calcular o volume. Desse modo, os alunos optaram por utilizar coordenadas polares, e a integral dupla obtida foi $\int_{0}^{2 \pi} \int_{0}^{3,34} 9,8 r d r d \theta$, que resultou em $343,26 \mathrm{~cm}^{3}$.

Em seguida, os três grupos fizeram 0 estudo da parte cônica da lata e optaram por modelar essa região por meio de um tronco de cone. Na Figura 3, apresentamos o esboço dessa região desenhado pelo grupo G2.

Figura 3 - Esboço da parte cônica do corpo da lata no espaço cartesiano desenhado por G2.

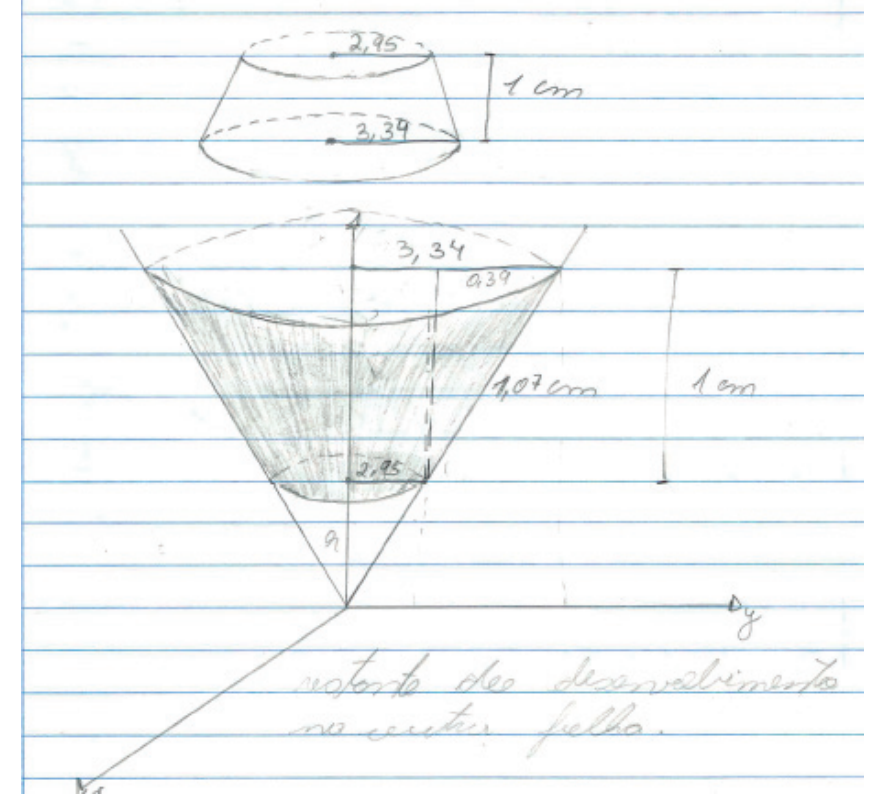

Fonte: Vidotti (2019, p. 177).

De forma semelhante aos procedimentos realizados para a parte cilíndrica, os alunos pesquisaram a equação do cone elíptico $\frac{z^{2}}{c^{2}} \frac{x^{2}}{a^{2}} \frac{y^{2}}{b^{2}}$, tomaram $a=b$ para obter a equação do cone circular $\mathrm{e}$ isolando a variável $z$, obtiveram $z=\frac{c}{a} \sqrt{x^{2}+y^{2}}$. Então, ao traçarem as seções transversais dessa superfície nos planos $x=0$ e $y=0$ puderam observar que a proporção c/a representava o coeficiente angular da reta diretriz do cone circular.

Segundo episódio de erro: Os alunos do grupo G2 tentaram calcular o coeficiente angular da reta diretriz do cone, identificando e calculando, primeiramente, as coordenadas dos pontos $A$ e $B$ , ilustrados no Quadro 2. Para isso, aplicaram o Teorema de Pitágoras no triângulo retângulo ACB a fim de determinar a medida do seguimento $A B$, denominada de $H_{1}{ }^{10}$. Em seguida, eles usaram a semelhança de triângulos, nos triângulos ODA e OEB a fim de determinar a medida $\mathrm{H}_{2}$, fazendo

10 Esta medida poderia ser obtida usando uma régua, a opção pelo cálculo foi justificada por questões de precisão, dificultada pelo formato irregular da lata. 
$\frac{3,34}{H_{1}+H_{2}}=\frac{2,95}{H_{2}}$. Contudo, ao aplicar essa técnica, parecem ter confundido os segmentos OE e OB, pois senão a soma $H_{1}+H_{2}$ não faria sentido, assim, entendemos que eles consideraram a soma $H_{1}+H_{2}^{\prime}$ em que $H_{2}^{\prime}$ é a medida do segmento $\mathrm{OB}$. Com isso, erraram também as coordenadas dos pontos A e $\mathrm{B}$, pois consideraram $A=\left(3,34 ; 1+H_{2}^{\prime}\right)$ e $B=\left(2,95 ; H_{2}^{\prime}\right)$. Além disso, inverteram a ordem dessas coordenadas (confundiram as coordenadas verticais com as horizontais e vice-versa), conforme mostra o recorte da resolução no Quadro 2.

Quadro 2 - Cálculos efetuados para obter o coeficiente angular da reta diretriz do cone

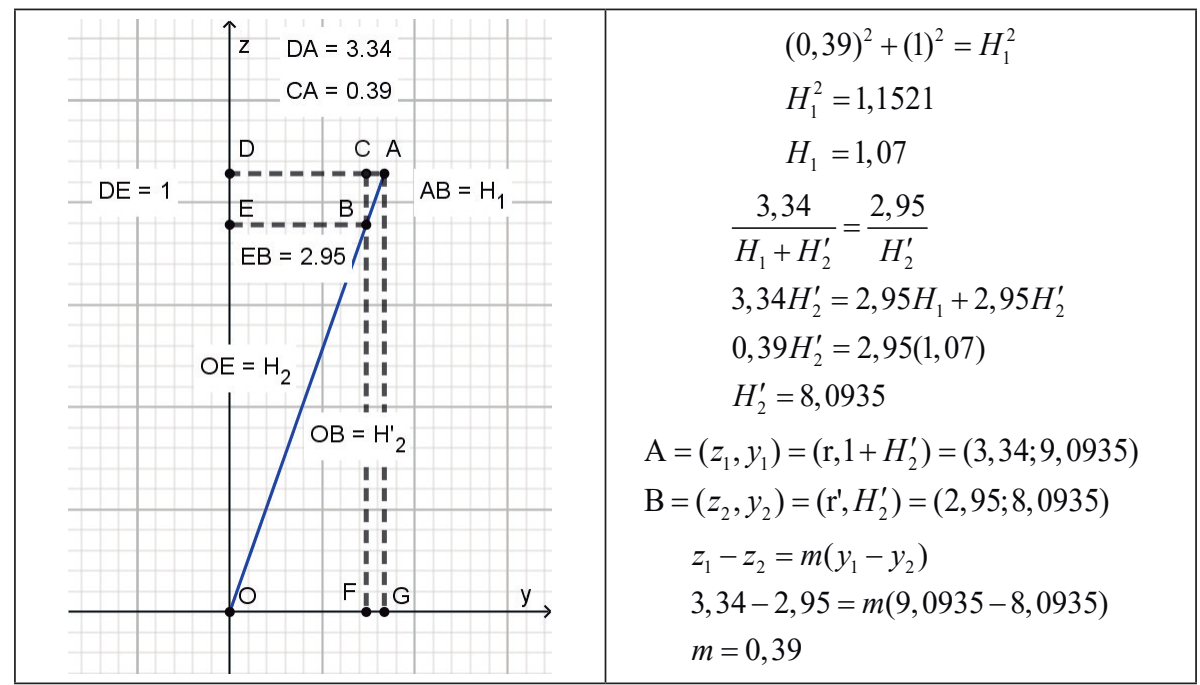

Fonte: Vidotti (2019, p. 178).

Contudo, sem perceber que haviam cometido esses erros, os alunos substituíram $\frac{c}{a}=\frac{39}{100}$ na equação $z=\frac{c}{a} \sqrt{x^{2}+y^{2}}$, obtendo $z=\frac{39}{100} \sqrt{x^{2}+y^{2}}$. Em seguida, aplicaram a integral dupla para calcular 0 volume dessa região cônica do corpo da lata e, ao finalizarem essa tarefa, perceberam que a medida do volume obtida para essa região, $87 \mathrm{ml}$, era incoerente com o problema real.

Então, ao examinarem os cálculos puderam reconhecer esses erros e corrigi-los, reescrevendo a relação proporcional $\frac{0,39}{1}=\frac{3,34}{x}$, na qual $x=1+H_{1}$ que resultou em $H_{1}=7,5641$. Assim, as coordenadas dos pontos $A$ e $B$ obtidas foram $A=(3,34 ; 8,5641)$ e $B=(2,95 ; 7,5641)$. Uma nova equação que representa a parte cônica da lata, $z=\frac{100}{39} \sqrt{x^{2}+y^{2}}$, foi determinada para 0 cálculo do seu volume, resultando em $31,097932 \mathrm{~cm}^{3}$. Essa medida somada ao volume da parte cilíndrica $\left(343,26 \mathrm{~cm}^{3}\right)$ resultou em aproximadamente $374 \mathrm{ml}$.

Vale destacar que nesta etapa de resolução do modelo matemático, os alunos não associaram o número obtido $(31,097932)$ com o problema real, visto que foram consideradas seis casas decimais no cálculo do volume, o que é incompatível com os instrumentos de medidas usuais, evidenciando momentos em que a resolução do modelo ocorre de forma desvinculada da realidade modelada. Esse fato pode ser observado também em outros momentos do desenvolvimento da atividade, descritos neste trabalho.

Na tentativa de validarem essa solução, os alunos perceberam que a latinha comporta uma quantidade de líquido um pouco maior do que aquela informada pelo fabricante $(350 \mathrm{ml})$. Para 
validarem 0 valor obtido, mediram a quantidade de água que a latinha comportava com auxílio de um copo graduado, e obtiveram $375 \mathrm{ml}$, aproximadamente.

0 episódio relatado ilustra a postura de remediação adotada pelos alunos, oportunizada pela atividade de Modelagem, a qual favoreceu que eles estimassem resultados parciais para o problema e com isso pudessem perceber o próprio erro, ao validarem suas respostas, considerando que eles tinham a informação do volume de conteúdo contido na lata. Nesse caso, o nível do discurso empreendido foi de tarefa, visto que o esforço realizado pelos alunos, após detectarem 0 erro, foi no sentido de "consertá-lo", buscando apenas corrigir os valores incorretos que utilizaram nas equações, de forma a realizar a tarefa com sucesso.

Terceiro episódio de erro: De forma semelhante, a postura de remediação também foi identificada nas ações dos alunos do G1, quando tentavam determinar o volume da parte cônica da lata. Nesse caso, posicionaram a parte cônica da lata imediatamente acima da parte cilíndrica em sua representação no espaço cartesiano (Figura 4). Assim, o vértice da superfície cônica ficou deslocado da origem do sistema e a equação do cone foi escrita como $z=-\frac{22}{10} \sqrt{x^{2}+y^{2}}+16,96$. Na Figura 5, ilustramos a superfície cônica com as denominações dadas no momento em que discutiam sobre 0 cálculo do volume.

Figura 4 - Gráficos das superfícies cônica e cilíndrica

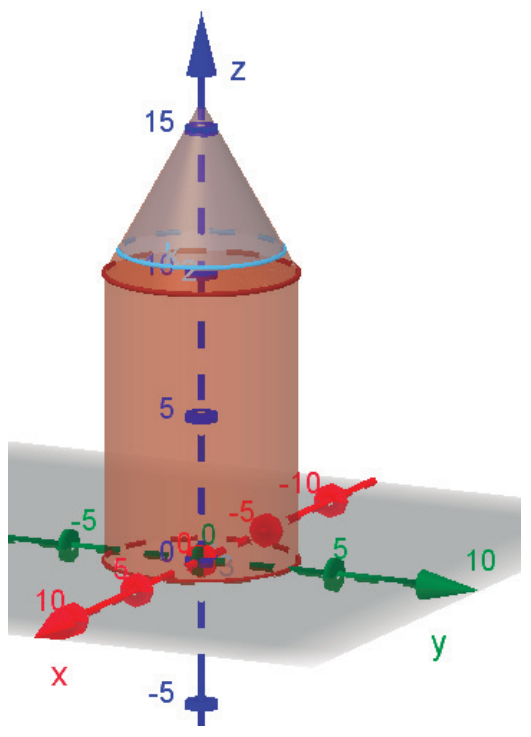

Fonte: Vidotti (2019, p. 183).
Figura 5 - Gráfico da superfície cônica com denominações de suas partes

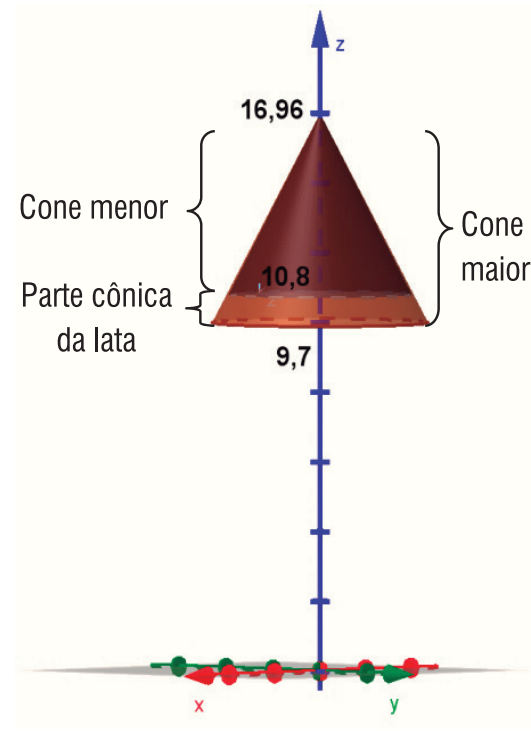

Fonte: Vidotti (2019, p. 184).

Para calcular o volume da superfície que representava a parte cônica da lata, eles procederam calculando as seguintes integrais duplas:

i) Volume do cone maior: $\int_{0}^{2 \pi 3} \int_{0}^{3}\left(-\frac{22}{10} \sqrt{r^{2}}+16,96\right) d r d \theta=414,6487$

ii) Volume do cone menor: $\int_{0}^{2 \pi} \int_{0}^{28}\left(-\frac{22}{10} \sqrt{r^{2}}+16,96\right) \cdot d r d \theta=316,5782$. 
A partir disso, subtraíram esses números, obtendo 98,0704 ml. Contudo, essa medida não correspondia à estimativa feita para o volume dessa região. Assim, eles optaram por examinar todos os cálculos efetuados e, com ajuda da professora/pesquisadora, perceberam que precisavam subtrair do volume obtido na primeira integral, o volume da região abaixo do plano $z=9,7 \mathrm{~cm}$ e a limitada pelo cilindro circular de raio $3,3 \mathrm{~cm}$, para obter o volume do "cone maior", indicado na Figura 5. Assim, a integral dupla (i) foi reescrita e calculada na forma:

$$
\int_{0}^{2 \pi} \int_{0}^{3,3}\left(-\frac{22}{10} \sqrt{r^{2}}+16,96-9,7\right) r d r d \theta=82,7929
$$

Do mesmo modo, eles precisavam subtrair do volume calculado na integral dupla (ii), o volume da região abaixo do plano $z=10,8 \mathrm{~cm}$, limitada pelo cilindro circular de raio $2,8 \mathrm{~cm}$, para obter 0 volume do "cone menor", indicado na Figura 5. Isto é:

$$
\int_{0}^{2 \pi} \int_{0}^{2,8}\left(-\frac{22}{10} \sqrt{r^{2}}+16,96-10,8\right) r d r d \theta=50,5739
$$

E ao subtraírem esses números concluíram que o volume da parte cônica da lata era 32,210 ml. Somando essa medida com 0 volume da parte cilíndrica, eles obtiveram $370,129 \mathrm{ml}$, que se aproximava da medida estimada para o volume total da lata.

Desse modo, identificamos nesse episódio uma postura de remediação, iniciada quando os alunos perceberam que 0 volume encontrado não correspondia à estimativa feita, medindo experimentalmente o líquido comportado pela lata. Essa postura os levou a identificarem um erro de interpretação geométrica do conceito de integral dupla. Dessa forma, entendemos que eles operaram em nível de discurso, conteúdo.

Os três episódios de erros descritos e analisados evidenciam diferentes usos dos erros desencadeados pela atividade de Modelagem. Considerando que nosso objetivo é identificar e discutir possibilidades para o uso dos erros matemáticos como oportunidades de aprendizagem de conceitos do CDI em uma atividade de Modelagem, sintetizamos no Quadro 3, as ocorrências dos usos específicos dos erros como trampolins para pesquisa ${ }^{11}$ na atividade "latinhas de alumínio", de acordo com as respectivas especificações do Quadro1.

Quadro 3 - Ocorrências de usos específicos dos erros na atividade "latinhas de alumínio"

\begin{tabular}{|c|c|c|c|}
\hline \multirow{2}{*}{$\begin{array}{c}\text { Postura de } \\
\text { Aprendizagem }\end{array}$} & $\begin{array}{c}|c| \\
\text { Realização de uma tarefa de discurso matemático } \\
\text { matemática específica }\end{array}$ & $\begin{array}{c}\text { Compreensão de algum } \\
\text { conteúdo técnico-matemático }\end{array}$ & $\begin{array}{c}\text { Compreensão sobre a } \\
\text { natureza da Matemática }\end{array}$ \\
\hline Remediação & $2^{0}$ episódio & $3^{0}$ episódio & \\
\hline Descoberta & & $1^{0}$ episódio & \\
\hline Pesquisa & & & \\
\hline
\end{tabular}

Fonte: Elaborado pelas autoras.

Observamos no Quadro 3 que as variações de usos dos erros denominados remediação/tarefa, remediação/conteúdo e descoberta/conteúdo evidenciam que essas estratégias são acessíveis aos

11 Refere-se a cada uma das nove maneiras possíveis de explorar os erros, conforme exibidas no Quadro 1. 
alunos em atividades de Modelagem envolvendo conceitos de CDI em várias variáveis. Além disso, essas posturas de aprendizagem, nos dois níveis de discurso matemático, foram exercidas espontaneamente pelos mesmos ao se submeterem a realizar uma atividade de Modelagem.

\section{CONCLUSÕES}

As discussões apresentadas nas seções anteriores amparam nossas reflexões em torno da questão: Que possibilidades de aprendizagem se revelam a partir dos erros cometidos pelos alunos em uma atividade de Modelagem Matemática envolvendo conceitos de Cálculo Diferencial e Integral? $\mathrm{Na}$ atividade de Modelagem desenvolvida pudemos observar as explorações realizadas pelos alunos ao intuírem que suas soluções poderiam estar incorretas. Estas explorações ilustram de que maneira os alunos de CDI podem usufruir dos erros cometidos por eles como trampolins para pesquisa, segundo Borasi (1996), em uma atividade de Modelagem, sugerindo algumas diferenças (em termos dos níveis do discurso matemático que eles podem ajudar a alcançar e dos objetivos de aprendizagem que eles podem facilitar) as quais influenciam no que os alunos podem aprender com a experiência.

Assumindo uma postura de descoberta, no primeiro episódio, uma vez que, os alunos não sabiam se a equação da circunferência determinada estava correta ou não, assim, tomaram consciência dos elementos do cilindro e identificaram 0 erro cometido ao escrever a equação que 0 define. Nesse sentido, tiveram a possibilidade de aprender sobre os elementos que caracterizam esse tipo de superfície (descoberta/conteúdo).

De forma semelhante, assumindo uma postura de remediação, visto que os alunos estavam certos de que as suas soluções estavam incorretas (segundo e terceiro episódios), eles examinaram essas soluções, e refletiram sobre a realização da tarefa, que se baseou na utilização da semelhança de triângulos, no segundo episódio. No terceiro episódio, consideramos que houve um aprofundamento do conteúdo de integrais duplas ao tomarem consciência do erro de interpretação geométrica desse conceito. Nesse sentido, entendemos que tiveram a possibilidade de aprender sobre como realizar a tarefa (remediação/tarefa); e sobre um conteúdo matemático interpretado de forma equivocada (remediação/conteúdo).

Ademais, inferimos outras possibilidades de aprendizagem, que o uso dos erros como trampolins para pesquisa pode oferecer aos alunos, particularmente em uma atividade de Modelagem.

Ao assumir uma abordagem de investigação para 0 ensino da matemática ${ }^{12}$, focada em erros, na qual os mesmos são vistos como trampolins para pesquisa, Borasi (1996) identificou e explicitou oportunidades de aprendizagem que podem ser propiciadas, quando os alunos assumem as diferentes variações dos usos dos erros:

(i) Vivenciar dúvidas e conflitos construtivos em relação às questões matemáticas. [...] (ii) Perseguir explorações matemáticas. [...] (iii) Engajar-se em desafiar a resolução de problemas matemáticos. [...] (iv) Vivenciar a necessidade de monitorar e justificar seu trabalho matemático. [...] (v) Vivenciar a iniciativa e apropriação em sua aprendizagem de matemática. [...] (vi) Refletir sobre a natureza da matemática. [...] (vii) Reconhecer os aspectos mais humanísticos da

\footnotetext{
12 Essa abordagem consiste em constituir um ambiente de aprendizagem fundamentado no seguinte conjunto de pressupostos sobre matemática, conhecimento, aprendizagem e ensino: (i) uma visão de matemática como disciplina humanista; (ii) uma visão do conhecimento como algo construído através de um processo de investigação; (iv) uma visão da aprendizagem como um processo gerador de significado, exigindo interação social e construção pessoal; (v) uma visão do ensino como estimulante e de apoio a própria investigação dos alunos (BORASI, 1996).
} 
matemática. [...] (viii) Verbalizar suas ideias matemáticas e comunicá-las (BORASI, 1996, p. 143-145, tradução nossa).

Assumindo que ao adotar a Modelagem como estratégia de ensino e aprendizagem de CDI, os alunos também adotaram algumas das variações dos usos dos erros, apontadas no Quadro 3, refletimos sobre algumas implicações em termos de oportunidades de aprendizagem:

- Vivenciar dúvidas e conflitos construtivos. No primeiro episódio de erro, a partir do erro na determinação da equação do cilindro, as alunas do G3 vivenciaram dúvidas e conflitos construtivos referentes à identificação dos elementos que constituem o cilindro. Isso porque tiveram que medir a latinha e estabelecer relações entre o próprio objeto e sua representação gráfica.

- Engajar-se em desafiar a resolução de problemas matemáticos. Durante o desenvolvimento da atividade de Modelagem os alunos envolveram-se em problemas matemáticos específicos, como quando tiveram que calcular as coordenadas dos pontos $A$ e $B$, ilustrados no Quadro 2, para determinar 0 coeficiente angular da reta diretriz do cone. Esse problema surgiu de um contexto real, 0 que pode parecer mais atraente e desafiador do que problemas que são normalmente inventados nos livros didáticos. Como pudemos observar, mesmo quando obtiveram respostas insatisfatórias, sentiram-se estimulados a explorar a sua solução até detectar o erro e corrigi-lo.

- Vivenciar a necessidade de monitorar e justificar seu trabalho matemático. De acordo com Borasi (1996) tal necessidade é consequência natural da dúvida e do conflito, causada por erros específicos, em que os alunos são levados a defender resultados que contrastam com outros, produzidos por um colega, por exemplo. No caso da atividade de Modelagem, os resultados contrastaram com as estimativas para o problema real. Isso fez com que, adotando uma postura de remediação, nos episódios dois e três, os alunos foram monitorando e justificando cada passo, até identificar 0 erro. Borasi (1996) afirma que essa postura é importante para mostrar ao aluno as consequências de uma interpretação superficial de um conteúdo matemático.

- Vivenciar a iniciativa e apropriação em sua aprendizagem de matemática. Borasi (1996) afirma que as dúvidas geradas por um erro podem convidar os alunos a levantar e explorar questões que são do seu interesse, proporcionando aos mesmos um maior sentimento de iniciativa e posse em sua aprendizagem de matemática. Na atividade desenvolvida, isso pôde ser observado, por exemplo, no terceiro episódio, em que os alunos esforçaram-se para entender o significado, em termos de volume, das integrais duplas (i) e (ii) que forneceram erroneamente os volumes dos cones menor e maior exibidos na Figura 5. Desse modo, envolveram-se em entender para onde 0 erro os levou. Além disso, ao assumirem a postura de remediação, analisaram e corrigiram seus erros sozinhos, o que, de acordo com Borasi (1996), contribui para proporcionar esse sentimento de posse de sua aprendizagem matemática. Ressalte-se, no que lhe concerne, em uma atividade de Modelagem, essa oportunidade de vivenciar iniciativa e apropriação em sua aprendizagem matemática também decorre da familiarização com o tema e do interesse em estudar a situação proposta, especialmente porque os mesmos definiram o problema real que iriam solucionar.

- Verbalizar suas ideias matemáticas e comunicá-las. Praticamente durante todo o desenvolvimento da atividade há evidências de que os alunos engajaram-se em comunicar suas ideias matemáticas (entre os membros do grupo e/ou com a professora/pesquisadora). A literatura de Modelagem aponta que a mesma é favorecedora de momentos nos quais os alunos discutem e expõem suas ideias matemáticas e não matemáticas (ARAÚJ0, 2002; BARBOSA, 2006), o que poderia por si só 
explicar tal ocorrência. Contudo, focando nos episódios de erro, também notamos uma necessidade de explicar (uns aos outros e/ou para a professora/pesquisadora) em que e porque erraram, bem como as dúvidas e ideias que surgiram na tentativa de corrigir esses erros.

As discussões apresentadas denotam o potencial de uma atividade de Modelagem para promover ao menos cinco, das oito oportunidades de aprendizagem elencadas por Borasi (1996), as quais podem ocorrer quando os alunos assumem as diferentes variações dos usos dos erros. É relevante salientar que, numa única atividade, é improvável que ocorram todas as nove variações dos usos dos erros apontadas no Quadro 1, o que justifica, de certa forma, a não ocorrência das demais oportunidades de aprendizagem supracitadas.

Para finalizar, é oportuno refletirmos acerca do papel do erro no contexto da Modelagem. Compreendemos que os alunos foram conduzidos a entender em que e porque erraram, para que pudessem realizar a atividade com sucesso e, nessa busca, desenvolveram novas explorações e descobertas. Particularmente, no caso de licenciandos em Matemática, extrapolam o âmbito do conteúdo específico do Cálculo, proporcionando experiências positivas que poderão converter em ações pedagógicas em suas futuras atividades como professores. Nesse viés, a atividade oportunizou aos licenciandos a compreensão dos erros não como fracassos, mas como parte dos processos de Modelagem e de aprendizagem.

\section{REFERÊNCIAS}

ALVES, F. R. V. Aplicações da Sequência Fedathi na promoção das categorias do raciocínio intuitivo no Cálculo a Várias Variáveis. 2011. 397 f. Tese (Doutorado em Educação) - Faculdade de Educação, Universidade Federal do Ceará, Fortaleza, 2011.

AÑINO, M. M. et al. Early error detection: an action-research experience teaching vector calculus. International Journal of Mathematical Education in Science and Technology, v. 45, n. 3, p. 378-395, 2014. Disponível em: https://bit.ly/3fc0o96. Acesso em: 15 ago. 2018.

ARAUJO, J. L. Cálculo, Tecnologias e Modelagem Matemática: as discussões dos alunos. 2002. $173 \mathrm{f}$. Tese (Doutorado em Educação Matemática) - Instituto de Biociências, Universidade Estadual Paulista Júlio de Mesquita Filho, Rio Claro, 2002.

ASTOLFI, J. P. El “error”, un medio para enseñar. Sevilla: Diada Editora S.L., 1999.

BARBOSA, J. C. Mathematical Modelling in classroom: a sócio-critical and discursive perspective. Zentralblatt für Didaktik der Mathematik, v. 38, n. 3, p. 293-301, 2006.

BARROS, M. C. de. Equações diferenciais ordinárias no contexto dos registros de representação semiótica e da modelagem matemática. 2017. 258 f. Tese (Doutorado em Educação para a Ciência e a Matemática) - Centro de Ciências Exatas, Universidade Estadual de Maringá, Maringá, 2017.

BASSANEZI, R. C. Ensino-aprendizagem com modelagem matemática: uma nova estratégia. São Paulo: Contexto, 2013.

BORASI, R. Using errors as springboards for the learning of mathematics: an introduction. Focus on Learning Problems in Mathematics, v. 7, n. 3-4, p. 1-14, 1985. 
BORASI, R. Reconceiving mathematics instruction: a focus on errors. Norwood, New Jersey: Ablex Publishing Corporation, 1996.

BORSSOI, A. H. A aprendizagem significativa em atividades de modelagem matemática como estratégia de ensino. 2004. 200 f. Dissertação (Mestrado em Ensino de Ciências e Educação Matemática) - Centro de Ciências Exatas, Universidade Estadual de Londrina, Londrina, 2004.

BRAGA, R. M. Modelagem matemática e tratamento do erro no processo de ensino-aprendizagem das equações diferenciais ordinárias. 2009. 180 f. Dissertação (Mestrado em Ciências e Matemáticas) - Instituto de Ciências Exatas e Naturais, Universidade Federal do Pará, Belém, 2009.

BRITO, C. E.; NUNES, T. R. Erros e Obstáculos no Processo de Aprendizagem de Derivadas: uma análise bilateral docente/discente. Educação Matemática em Revista. Brasília, v. 22, n. 56, p. 277-288, out./dez. 2017.

CAMPO, I. S.; ARAÚJO, J. L. Quando pesquisa e prática pedagógica acontecem simultaneamente no ambiente de modelagem matemática: problematizando a dialética pesquisador/professor. Acta Scientiae, Canoas, v. 17, n. 2, p. 324-339, maio/ago. 2015.

CURY, H. N. Análise de erros: 0 que podemos aprender com as respostas dos alunos. Belo Horizonte: Autêntica, 2008.

CURY, H. N. As concepções matemáticas dos professores e suas formas de considerar os erros dos alunos. 1994. Tese (Doutorado em Educação) - Faculdade de Educação, Universidade Federal do Rio Grande do Sul, Porto Alegre, 1994.

FRANCHI, R.H.O.I. A Modelagem Matemática como estratégia de aprendizagem do cálculo diferencial e integral nos cursos de engenharia. 1993. 143 f. Dissertação (Mestrado em Educação Matemática) - Instituto de Biociências, Universidade Estadual Paulista Júlio de Mesquita Filho, Rio Claro, 1993.

GARNICA, A. V. M. História Oral e educação Matemática. In: BORBA, M. de C.; ARAÚJO, J. de L. (orgs.) Pesquisa Qualitativa em Educação Matemática. Belo Horizonte: Autêntica, 2004.

KASHEFI, H., ZALEHA I.; YUDARIAH M. Y. Obstacles in the Learning of Two-variable Functions through Mathematical Thinking Approach. Procedia-Social and Behavioral Sciences, v. 8, p. 173-180, 2010.

KASHEFI, H., ZALEHA I.; YUDARIAH; M. Y. Students' Difficulties in Multivariable Calculus through Mathematical Thinking Approach. Journal of Edupres, v. 1, p. 77-86, 2011.

KASHEFI, H.; ZALEHA, I.; YUDARIAH M. Y. Overcoming Students Obstacles in Multivariable Calculus through Blended Learning: A Mathematical Thinking Approach. Procedia-Social and Behavioral Sciences, v. 56, p. 579-586, 2012. Disponível em: https://bit.ly/3fbF8Ay. Acesso em: 12 ago. 2018.

KASHEFI, H.; ISMAIL, Z.; YUSOF, M.; RAHMAN, R. Supporting Students Mathematical Thinking in the Learning of Two-Variable Functions Through Blended Learning. Procedia-Social and Behavioral Sciences, v. 46, p. 3689-3695, 2012. Disponível em: https://bit.ly/3gbVb2D. Acesso em: 12 ago. 2018.

KLÜBER, T. E. Uma meta compreensão da Modelagem Matemática na Educação Matemática. 2012. Tese (Doutorado em Educação Científica e Tecnológica) - Centro de Ciências Físicas e Matemática, Universidade Federal de Santa Catarina, Florianópolis, 2012. 
MÜLLER, T. J. Objetos de aprendizagem multimodais e ensino de Cálculo: uma proposta baseada em análise de erros. 2015. 203 f. Tese (Doutorado em Informática da Educação) - Centro de Estudos Interdisciplinares em Tecnologia na Educação, Universidade Federal do Rio Grande do Sul, Porto Alegre, 2015.

ROCHA, M. M.; WAGNER, V. M. P dos S. Impactos de análise de acertos e erros em cálculo I. Vydia, Santa Maria, v. 37, n. 2, p. 367-382, jul./dez., 2017.

SANTOS, F. V. Modelagem matemática e tecnologias de informação e comunicação: 0 uso que os alunos fazem do computador em atividades de modelagem. 2008. 197 f. Dissertação (Mestrado em Ensino de Ciências e Educação Matemática) - Centro de Ciências Exatas, Universidade Estadual de Londrina, Londrina, 2008.

STEWART, J. Cálculo. v. 1 e 2, 6. ed., São Paulo: Cengage Learning, 2011.

VERTUAN, R. E. Um olhar sobre a modelagem matemática à luz da teoria dos registros de representação semiótica. 2007. 141 f. Dissertação (Mestrado em Ensino de Ciências e Educação Matemática) - Centro de Ciências Exatas, Universidade Estadual de Londrina, Londrina, 2007.

VIDOTTI, D. B.; KATO, L. A. Um estudo sobre conflitos no processo de aprendizagem de limite de funções de várias variáveis. Acta Scientiae, Canoas, v. 20, n. 5, p. 730-749, set./out. 2018.

VIDOTTI, D. B. Potencialidades da modelagem matemática e da análise de erros para 0 ensino e a aprendizagem de cálculo diferencial e integral em várias variáveis. 2019. Tese (Doutorado em Educação para a Ciência e a Matemática) - Centro de Ciências Exatas, Universidade Estadual de Maringá, Maringá, 2019.

RECEBIDO EM: 04 nOv. 2019

CONCLUÍDO EM: 10 fev. 2019 
